\title{
A iminente importância da orientação profissional para uma escolha de carreira assertiva
}

\section{Maria Luiza Mariano}

Faculdade Anhanguera de Bauru (FAB), Bauru - SP - Brasil. Coordenadora e Professora do Curso de Pedagogia e Psicologia. E-mail: maria.lalegria@anhanguera.com

\section{Luiz Miguel Batista de Moraes}

Faculdade Anhanguera de Bauru (FAB), Bauru - SP - Brasil. Graduando em Psicologia.

\section{Minoru Miazaki}

Faculdade Anhanguera de Bauru (FAB), Bauru - SP - Brasil. Graduando em Psicologia. 


\section{Resumo}

O presente propõe uma revisão bibliográfica criteriosa, com a finalidade de elucidar e clarificar, a priori, sobre o processo de orientação profissional e sua importância para a construção de ações que favorecem para uma escolha de carreira profissional assertiva, sob constructo do desenvolvimento pessoal e profissional atrelados ao autoconhecimento, no sentido de que se trata de um processo fundamental dentro da orientação profissional, visto que é uma estratégia capaz de fazer os jovens refletirem sobre o que sabem fazer, o que gostam, o que as pessoas pensam sobre eles, dentre outras possibilidades e também fazer com que os indivíduos participantes do processo tenham consciência sobre as vertentes do mundo de trabalho e a sua participação na sociedade.

Palavras-chave: orientação profissional, desenvolvimento pessoal e profissional, contexto escolar, autoconhecimento, adolescência, mercado de trabalho.

\section{Abstract}

This paper proposes a careful bibliographical review with the purpose of elucidating and clarifying, a priori, the process of professional orientation and its importance for the construction of actions that favor a choice of assertive professional career, under the construct of personal and professional development linked to self-knowledge, in the sense that it is a fundamental process within the professional orientation, since it is a strategy capable of making young people reflect on what they know how to do, what they like, what people think about them, among others possibilities and also to make the individuals involved in the process aware of the aspects of the world of work and their participation in society.

Keywords: professional orientation, personal and professional development, school context, self-knowledge, adolescence, labor market. 


\section{Introdução}

Com o avanço mercadológico, cada vez mais os sujeitos a ele envolvidos necessitam de desenvolvimento e atualização profissional.

O processo de orientação profissional evidencia-se como um fator de suma importância para que esse desenvolvimento ocorra, e de maneira assertiva, proporcionando estratégias que favoreçam a aquisição e assimilação sobre qual a "melhor escolha profissional", possibilitando que as dúvidas, as dificuldades e falta de aclaração por parte de determinados indivíduos sejam sanadas durante esse processo.

$\mathrm{Na}$ atualidade, os jovens não conseguem se planejar e projetar-se para o seu futuro de maneira adequada, ou, quando, conseguem, esse futuro idealizado é irreal, causando-nos frustrações.

Segundo Lisboa (2017, p. 112) se faz necessário uma preparação desde os primórdios da educação básica, em que o indivíduo tenha uma formação efetiva para a realidade do trabalho, em outras palavras a formação para a vida, quando seja possibilitados o desenvolvimento e construção de identidade, de forma a compreenderem primeiramente a si mesmos.

Nesse importante processo vale salientar a iminente e relevante possibilidade de desenvolvimento e exercício do autoconhecimento que é uma significativa característica que auxilia para a realização da escolha profissional, auxiliando para que sejam evitados sentimentos de angústia, ansiedade, indecisão, associados a essa escolha, além de o autoconhecimento ser uma considerável característica que contribui diretamente na construção da identidade profissional.

O processo de orientação profissional desenvolve os indivíduos de maneira ética e moral possibilitando que os mesmos se adaptem às transformações e tendências sociais mercadológicas capitalistas, à globalização e aos avanços tecnológicos, que atualmente vêm exigindo profundas modificações, tanto nas organizações como na vida das pessoas.

Segundo Rodrigues \& Ramos (2000) tais avanços são evidenciados como um impacto em todas as áreas da vida, sendo assim imprescindível o desenvolvimento de competências, habilidades e atitudes, como o trabalho em equipe e a criatividade. É necessário que as pessoas estejam envolvidas com a realidade contemporânea, e estejam antenadas, engajadas a toda a possibilidade de desenvolvimento.

Diante do exposto, entende-se que a orientação profissional pode proporcionar inúmeras contribuições aos indivíduos envolvidos no processo. Desse modo pergunta-se: qual é a eminente importância da Orientação Profissional para o desenvolvimento pessoal e profissional de indivíduos no contexto educacional?

O objetivo desta pesquisa é compreender e viabilizar o conhecimento sobre a importância da orientação profissional no contexto educacional como ferramenta que auxilia na busca e construção de competências, habilidades e atitudes que corroboram para a concepção e construção do autoconhecimento, desenvolvimento pessoal e profissional, como fator primordial no processo de escolha profissional, bem como a importância da participação ética e moral do indivíduo no mundo do trabalho enquanto agente social atuante. 
A utilização dos meios de pesquisa para a fundamentação deste, com a finalidade de investigação bibliográfica criteriosa, corresponde à base de dados de estudos contundentes, nacionais e internacionais, especificamente construído por repertórios publicados em livros, revistas, artigos científicos, dissertações e teses acadêmicas; na perspectiva sobre a temática de amputação, dor fantasma, impactos biológicos, impactos psicológicos e impactos sociais, visando o desenvolvimento assertivo e embasamento primoroso do trabalho.

\section{Fundamentação Teórica}

\section{A orientação profissional como peça fundamental no processo de escolha de carreira.}

O ensino médio é o período da vida dos jovens que os questionamentos são constantes, sobre qual curso fazer e qual profissão seguir. Trata-se de um processo que envolve múltiplos fatores que cooperam para a indecisão, quando o fator social e a falta de amparo educacional fortalecem o sentimento de insegurança nos indivíduos. (ANDRADE e JUNIOR. s.d).

A carreira e a escolha profissional podem ser constituídas por uma sequência ou combinação de diversos fatores e papéis sociais, que são desempenhados por um determinado indivíduo ao longo de sua vida. Os determinantes que podem interferir nessa escolha são sociais, educacionais, econômicos, políticos, familiares e psicológicos. (Neiva, 2005).

Quando o foco se torna em desenvolver conhecimentos, habilidades e atitudes que facilitam essa transição de papéis de maneira saudável, a orientação profissional entra em cena como ferramenta primordial capaz de viabilizar inúmeras possibilidades de intervenções que auxiliam no progresso pessoal e profissional de um determinado indivíduo.

O processo de orientação profissional não define qual carreira ou área profissional o indivíduo deve atuar, mas sim, possibilita que a pessoa seja orientada a "orientar-se", ou seja, reconhecer a situação do lugar onde se acha, para guiar-se no seu próprio caminho".

A partir dos conhecimentos administrados por um profissional psicólogo capacitado, o indivíduo, pertencente ao processo de orientação profissional, é capaz de tomar decisões por si próprio, agora refutado de conhecimento que embasa e auxilia a formular suas aspirações, a descobrir caminhos para soluções, estimulando-os na procura que lhes parece mais apropriada.

O objetivo da orientação profissional é capacitar indivíduos a construir um modelo representativo e adequado para lidar com as transições e mudanças da vida, não envolvendo apenas as esferas escolares e profissionais, mas também pessoais.

A orientação profissional define-se como um processo que facilita a uma escolha profissional, porém, que esteja atrelada ou em sintonia com o conhecimento de si mesmo e da realidade do mercado de trabalho em que se insere o indivíduo orientando; uma escolha feita reflexivamente, no sentido de a pessoa se assumir como responsável por si própria capaz de realizar a futura escolha. (BRASIL, 2012). 


\section{O autoconhecimento e sua importância para o desenvolvimento pessoal e profissional.}

O processo de orientação profissional apresenta-se como uma ferramenta crucial, não somente para auxiliar na escolha de carreira, mas antes disso, como uma importante peça que subsidia e proporciona o autoconhecimento.

Bardagi, Arteche e Neiva-Silva 2005, consideram o processo como elucidador, pois levam os indivíduos envolvidos ao autoconhecimento, que caracteriza-se e enfatiza-se como momento de construção da responsabilidade e da autonomia no orientando, sendo este principal precursor de sua própria decisão, ou seja a Orientação profissional vincula-se a três modalidades: o conhecimento de si mesmo, o conhecimento das profissões e a integração desses aspectos em uma síntese pessoal.

É imprescindível proporcionar ao jovem oportunidades para pensar em si mesmo, a refletir no seu cotidiano, conscientizando-o das percepções de si mesmo em relação as habilidades que possui e que precisa desenvolver, desta forma através do processo de orientação profissional (SOARES 2002, p.88),

Partindo disso, Andrade 2002 aponta que a função do orientador é facilitar o acesso às informações sobre profissões, mercado de trabalho, ou seja, facilitando o autodesenvolvimento do orientando.

$\mathrm{O}$ autor ainda ressalta que o processo de orientação profissional é continuo e leva ao autoconhecimento, não devendo ser encarado apenas como oportunidades para falar sobre carreiras e sim como uma oportunidade para oferecer condições para que o adolescente reflita e faça sua escolha de forma amadurecida, em que a melhor escolha seria aquela a qual o mesmo realiza a partir de um maior conhecimento sobre si, levando em conta seus interesses, habilidades, sendo que estes não são estáticos, podendo sofrer mudanças conforme as vivencias e o passar do tempo. (ANDRADE, 2002)

Segundo Lisboa e Soares (2017. p. 24) o orientador é considerado como alguém que porta uma lanterna, iluminando a escuridão, procurando desvendála, conhecendo-a juntamente ao seu orientando; pode-se então enfatizar que o orientador é mais do que um elucidador de possibilidades de atuação, mas um profissional que assume a responsabilidade moral e ética de trilhar o caminho em conjunto com seu orientando, para assim identificar onde este pode chegar.

\section{A contribuição social mediante a escolha de carreira}

As transformações sociais mercadológicas capitalistas, a globalização e os avanços tecnológicos vêm exigindo profundas modificações, tanto nas organizações como na vida das pessoas. Segundo Rodrigues \& Ramos (2000) tais avanços é evidenciado como um impacto em todas as áreas da vida, sendo assim imprescindível o desenvolvimento de competências e habilidades, como o trabalho em equipe e a criatividade na busca de melhores resultados profissionais e pessoais.

Partindo disso, Soares (2002) discorre que o processo de escolha profissional é bastante complexo, demandando conhecimento não apenas técnicos, mas, também o conhecimento de si. 
Diversos fatores são determinantes na escolha profissional e sofrem interferências do sistema político e social vigente; o autor ainda discorre a respeito da complexidade de fatores intermitentes no processo de escolha profissional, onde as contribuições sociais estão atreladas a fatores econômicos e a falta de oportunidade e aclaração dentro do contexto escolar. (SOARES, 2002).

Segundo a Lei de Diretrizes e Bases da Educação Nacional (Lei no 9.394/96) no ensino médio devido as constantes transformações de ordem tecnológica e econômica financeira, exige um novo profissional com uma educação diferenciada. A LDB, objetiva consolidar e aprofundar os conhecimentos adquiridos na educação fundamental, desenvolver a compreensão e o domínio dos fundamentos científicos e tecnológicos que presidem a produção moderna.

O mercado de trabalho exige um profissional plurivalente e bem orientado, porém, de acordo com Costa 2000, o modelo de orientação profissional, em que cada profissão tem características pessoais, que dita um padrão a ser seguido e se enquadra como obsoleto, ainda acrescenta que "embora isso seja verdade, há uma busca mítica pela orientação profissional, a crença de que o processo traga uma resposta mágica e solucione as angústias decorrentes da escolha de uma profissão".

De acordo com Esteves (2014), o mercado de trabalho vem tornando-se cada vez mais competitivo, tendo em vista as mudanças ocorridas pósglobalização na economia, politica, relações sociais e com os avanços tecnológicos, de forma que muitos estudiosos têm se voltado a estudar sobre tais modificações. Partindo disso, Soares (2002) discorre que o processo de escolha profissional é bastante complexo, demandando conhecimento não apenas técnico, mas, também o conhecimento de si.

O processo de orientação profissional vai além de uma demanda préexistente, engloba múltiplos fatores que influenciam os jovens na tomada de decisão, para tanto o amparo elucidativo nesse período é crucial, visto que permite com que os mesmos tenham um posicionamento mercadológico e as possibilidades de atuação.

Para Brasil ( 2012) o mundo de trabalho na contemporaneidade requer novas ações dos indivíduos em relação as decisões profissionais, não sendo este limitado a somente a um momento e sim a uma busca sistemática de mudanças, pois o fator escolha percorre por toda a vida destes, em que a inserção no mercado de trabalho permeia períodos transitórios, onde $o$ autodesenvolvimento é crucial, exigindo assim, continuas reflexões sobre o seu papel enquanto um ser social. (BRASIL, 2012).

\section{Considerações Finais}

Mediante os estudos estabelecidos, verifica-se que o Processo de Orientação Profissional é de grande valia, sendo introduzido com a finalidade de favorecer a construção de um projeto de vida com a atuação e desenvolvimento de competências, habilidades e atitudes, tão importantes para o 
desenvolvimento pessoal e profissional de um indivíduo, mediante as demandas mercadológicas e sociais existentes, que são tão exigidas na atualidade.

A orientação profissional se baseia nos eixos sobre autoconhecimento, conhecimento das profissões e suas relações sociais, sobre as pluralidades e possibilidades de escolha considerando as mudanças mercadológicas. Dá ênfase nas habilidades que instrumentalizam o indivíduo, possibilitando a torná-lo observador mais acurado de seu próprio conhecimento, de forma a compreender sobre as alternativas de formação, treinamentos específicos, requisitos e práticas pertinentes a carreira escolhida, ou seja, de certa forma, a proporcionar ao orientando a clarificação e inserção ao progresso.

O processo de orientação profissional denomina-se em levar o orientando a refletir sobre as profissões, as influências, as possibilidades e impossibilidades que as mesmas podem acarretar a eles. O orientador deve favorecer, por meio das técnicas e intervenções admoestadas, que o jovem venha descobrir seu caminho, coordenar seus questionamentos e descobertas de maneira emancipada, devendo arcar com as satisfações e insatisfações de ter que posicionar-se e escolher.

Para tanto é importante ressaltar que a orientação profissional é um processo tão importante, que deveria ser uma exigência curricular e realizada pelo profissional de orientação profissional, porém, sabe-se que tal apoio é ofertado somente em foros privilegiados, sendo em algumas escolas particulares, evidenciado assim, infelizmente, a falta de oportunidades para outros públicos em camada social baixa.

Pode-se então concluir que este processo é iminentemente importante, e colabora para que a efetiva escolha profissional ocorra, ou seja, torna-se possível quando o jovem atinge o conceito de si, no momento em que se percebe o trabalho que se adequa ao seu perfil, o autoconceito, ou autoconhecimento de si, baseando-se nas identificações e desempenho de papéis, porém, destacandose que a escolha profissional nunca é única e definitiva, que sempre há uma escolha possível, dentro de diversas possibilidades e contingências.

\section{Referências}

ANDRADE, J. M. de; Meira, G. R. J. M; Vasconcelos, Z. B. O processo de orientação vocacional frente ao século XXI: perspectivas e desafios. Psicol. cienc. prof., Brasília, v. 22, n. 3, p. 46-53, Sept. 2002. Disponível em: <http://www.scielo.br/scielo.php?script=sci_arttext\&pid=S141498932002000 300008\&lng=en\&nrm=iso $>$. Acesso em: 08/06/2019

ANDRADE, M. Josemberg, JUNIOR, S. Misael. O Autoconhecimento e a Escolha profissional. Disponível em: http://www.prac.ufpb.br/enex/trabalhos/4CCHLADPPROBEX2013567.pdf. Acesso em: 03/06/2019

BARDAGI, M. P.; ARTECHE, A. X.; NEIVA-SILVA, L. Projetos sociais com adolescentes em situação de risco: Discutindo o trabalho e a orientação profissional como estratégias de intervenção. In: C. Hutz 
(Org.), Violência e risco na infância e na adolescência: Pesquisa e intervenção. São Paulo: Casa do Psicólogo, 2005. p. 104-146.

BRASIL. Vanderlei, et al. Orientação Profissional e Planejamento de Carreira Para Universitários. Disponível em:

http://www.portaldeperiodicos.unisul.br/index.php/Cadernos Academicos/article/do wnload/1213/1015Acesso em: 09/06/2019

COSTA, Janaina Moutinho. Orientação profissional: um outro olhar. Psicologia USP, São Paulo, v.18, n.4, dez. 2000.

DOMINGUES, José Juiz; TOSCHI, Nirza Seabra; OLIVEIRA, João Ferreira de. A reforma do Ensino Médio: a nova formulação curricular e a realidade da escola pública. Educação e Sociedade, Campinas, v. 21, n. 70, abr. 2000.

ESTEVES, Eliel Soares. Fatores que influenciam nas escolhas profissionais dos jovens do ensino médio das escolas públicas e privadas do município de Espigão d' Oeste-RO. $31 \mathrm{f}$. Trabalho de Conclusão de Curso (Bacharelado em Administração) - Universidade Federal de Rondônia, Cacoal, 2014.

GOLIN, J. (2000). O adolescente e o processo de escolha profissional. Trabalho apresentado na I Jornada Norte - Nordeste de Orientação Profissional/ ABOP, Recife.

JORDANI. S. Paulo, et al. Fatores determinantes na escolha profissional: um estudo com alunos concluintes do ensino médio da região Oeste de Santa Catarina. Disponível

em: http://www.admpg.com.br/revista2014 2/Artigos/3\%20-\%20Artigo 3.pdf. Acesso em: $10 / 06 / 2019$

LISBOA. D.Marilu; SOARES. P. L. Dulce. Orientação profissional em ação. São Paulo: SUMMUS, 2017. 12 ,13 e 22 p.

NEIVA, K. M. C. et al . Um estudo sobre a maturidade para a escolha profissional de alunos do ensino médio. Rev. bras. orientac. prof, São Paulo, v. 6, n. 1, p. 1-14, jun. 2005. Disponível em:

$<$ http://pepsic.bvsalud.org/scielo.php?script=sci_arttext\&pid=\$167933902005 o00100002\&lng $=$ pt\&nrm=iso $>$. Acesso em: 11/06/2019

Presidência da República Casa Civil. Subchefia para Assuntos Jurídicos. Lei No 9.394, de 20 De dezembro de 1996. Disponível em: http://www.planalto.gov.br/ccivil $03 /$ Leis/l9394.htm. Acesso em: 12/o6/2019

RODRIGUES, E., Ramos, S.G. (2000). Domínio de técnicas garante eficiência profissional. Trabalho apresentado na I Jornada Norte Nordeste de Orientação Profissional/ ABOP, Recife. 
ALEGRIA, M.L.M; MORAES, L. M. B.; MIAZAKI,M.. A iminente importância da orientação profissional para uma escolha de carreira assertiva. R. Científica UBM - Barra Mansa (RJ),

ano XXIX, v. 21, n. 41, 2. Sem. 2019. p. 178-188.

ISSN 1516-4071

SOARES, Dulce Helena Penna. A escolha profissional: do jovem ao adulto. $2^{\text {a }}$ edição - Sumus: 2002, São Paulo. 